\title{
ON GLOBAL IN TIME EXISTENCE OF SOLUTIONS TO STOCHASTIC EQUATIONS WITH BACKWARD MEAN DERIVATIVES
}

\author{
Yu. E. Gliklikh ${ }^{1}$, yeg@math.vsu.ru, \\ N. V. Zakharov ${ }^{1}$, punk74@rambler.ru \\ ${ }^{1}$ Voronezh State University, Voronezh, Russian Federation
}

\begin{abstract}
The notion of mean derivatives was introduced by E. Nelson in 60-th years of XX century and at the moment there are a lot of mathematical models of physical and technical processes constructed in terms of equations with those derivatives. The paper is devoted to investigation of stochastic differential equations with backward mean derivatives. This type of equations arise in several models of physical and technical processes and so its investigation is important for applications. But on the other hand, the investigation of such equations requires new methods and ideas. In this paper we deal with the property of global in time existence of all solutions of "inverse" Cauchy problem for equations with backward mean derivatives. A condition that guarantees the global in time existence of such solutions is obtained. This result is useful for many mathematical models of physical and technical processes.

Keywords: backward mean derivatives; stochastic equations; global existence of solutions.
\end{abstract}

\section{Introduction}

The notion of mean derivatives was introduced by Edward Nelson (see. [1-3]) for the needs of stochastic mechanics (a version of quantum mechanics). The equation of motion in this theory (called the Newton-Nelson equation) was the first example of equations in mean derivatives. Later it turned out that the equations in mean derivatives arose also in many other mathematical models in mathematical physics.(see, e.g., [4,5]).

The equations with backward mean derivatives arise in description of some special stochastic processes of mathematical physics. Say, a second order equation in backward mean derivatives of the group of Sobolev diffeomorphisms is derived that describes a process whose expectation is a flow of viscous incompressible fluid (see, e.g., [4,5]). It should be pointed out that such equations are much more complicated for investigation than those with forward mean derivatives. Nevertheless there exists a simple method of using inverse time direction for solutions of equations with forward mean derivatives (see, e.g., [6]), that allows one to obtain some results for the case of backward mean derivatives. In this paper we find a sufficient condition for global in time existence of all solutions of "inverse" Cauchy problem for such equations.

Some remarks on notations. In this paper we deal with equations and inclusions in the linear space $\mathbb{R}^{n}$, for which we use coordinate presentation of vectors and linear operators. Vectors in $\mathbb{R}^{n}$ are considered as columns. If $X$ is such a vector, the transposed row vector is denoted by $X^{*}$. Linear operators from $\mathbb{R}^{n}$ to $\mathbb{R}^{n}$ are represented as $n \times n$ matrices, the symbol $*$ means transposition of a matrix (pass to the matrix of conjugate operator). The space of $n \times n$ matrices is denoted by $L\left(\mathbb{R}^{n}, \mathbb{R}^{n}\right)$. 
By $\mathrm{S}(n)$ we denote the linear space of symmetric $n \times n$ matrices that is a subspace in $L\left(\mathbb{R}^{n}, \mathbb{R}^{n}\right)$. The symbol $\mathrm{S}_{+}(n)$ denotes the set of positive definite symmetric $n \times n$ matrices that is a convex open set in $\mathrm{S}(n)$. Its closure, i.e., the set of positive semi-definite symmetric $n \times n$ matrices, is denoted by $\overline{\mathrm{S}}_{+}(n)$.

\section{Mean Derivatives}

In this section we briefly describe preliminary facts about mean derivatives. See details in $[1-3,5]$.

Consider a stochastic process $\xi(t)$ in $\mathbb{R}^{n}, t \in[0, T]$, given on a certain probability space $(\Omega, \mathcal{F}, \mathrm{P})$ and such that $\xi(t)$ is an $L_{1}$ random element for all $t$. It is known that such a process determines 3 families of $\sigma$-subalgebras of the $\sigma$-algebra $\mathcal{F}$ :

(i) "the past" $\mathcal{P}_{t}^{\xi}$ generated by preimages of Borel sets from $\mathbb{R}^{n}$ under all mappings $\xi(s): \Omega \rightarrow \mathbb{R}^{n}$ for $0 \leq s \leq t$

(ii) "the future" $\mathcal{F}_{t}^{\xi}$ generated by preimages of Borel sets from $\mathbb{R}^{n}$ under all mappings $\xi(s): \Omega \rightarrow \mathbb{R}^{n}$ for $t \leq s \leq T$

(iii) "the present" ("now") $\mathcal{N}_{t}^{\xi}$ generated by preimages of Borel sets from $\mathbb{R}^{n}$ under the mapping $\xi(t): \Omega \rightarrow \mathbb{R}^{n}$.

All the above families we suppose to be complete, i.e., containing all sets of probability zero.

For the sake of convenience we denote by $E_{t}^{\xi}$ the conditional expectation $E\left(\cdot \mid \mathcal{N}_{t}^{\xi}\right)$ with respect to the "present" $\mathcal{N}_{t}^{\xi}$ for $\xi(t)$.

Following [1-3], introduce the following notions of forward and backward mean derivatives.

Definition 1. (i) The forward mean derivative $D \xi(t)$ of $\xi(t)$ at the time instant $t$ is an $L_{1}$ random element of the form

$$
D \xi(t)=\lim _{\triangle t \rightarrow+0} E_{t}^{\xi}\left(\frac{\xi(t+\triangle t)-\xi(t)}{\triangle t}\right)
$$

where the limit is supposed to exist in $L_{1}(\Omega, \mathcal{F}, \mathrm{P})$ and $\triangle t \rightarrow+0$ means that $\triangle t$ tends to 0 and $\triangle t>0$.

(ii) The backward mean derivative $D_{*} \xi(t)$ of $\xi(t)$ at $t$ is the $L_{1}$-random element

$$
D_{*} \xi(t)=\lim _{\Delta t \rightarrow+0} E_{t}^{\xi}\left(\frac{\xi(t)-\xi(t-\Delta t)}{\Delta t}\right)
$$

where (as well as in (i)) the limit is assumed to exist in $L^{1}(\Omega, \mathcal{F}, \mathrm{P})$ and $\Delta t \rightarrow+0$ means that $\Delta t \rightarrow 0$ and $\Delta t>0$.

Remark 1. If $\xi(t)$ is a Markov process then evidently $E_{t}^{\xi}$ can be replaced by $E\left(\cdot \mid \mathcal{P}_{t}^{\xi}\right)$ in (1) and by $E\left(\cdot \mid \mathcal{F}_{t}^{\xi}\right)$ in (2). In initial Nelson's works there were two versions of definition of mean derivatives: as in our Definition 1 and with conditional expectations with respect to "past" and "future" as above that coincide for Markov processes. We shall not suppose $\xi(t)$ to be a Markov process and give the definition with conditional expectation with respect to "present" taking into account the physical principle of locality: the derivative should be determined by the present state of the system, not by its past or future. 
Following [6] we introduce the differential operator $D_{2}$ that differentiates an $L_{1}$ random process $\xi(t), t \in[0, T]$ according to the rule

$$
D_{2} \xi(t)=\lim _{\triangle t \rightarrow+0} E_{t}^{\xi}\left(\frac{(\xi(t+\triangle t)-\xi(t))(\xi(t+\Delta t)-\xi(t))^{*}}{\triangle t}\right),
$$

where $(\xi(t+\triangle t)-\xi(t))$ is considered as a column vector (vector in $\left.\mathbb{R}^{n}\right),(\xi(t+\triangle t)-\xi(t))^{*}$ is a row vector (transposed, or conjugate vector) and the limit is supposed to exists in $L_{1}(\Omega, \mathcal{F}, \mathrm{P})$. We emphasize that the matrix product of a column on the left and a row on the right is a matrix so that $D_{2} \xi(t)$ is a symmetric semi-positive definite matrix function on $[0, T] \times \mathbb{R}^{n}$. We call $D_{2}$ the quadratic mean derivative.

Remark 2. From the properties of conditional expectation (see, e.g., [7]) it follows that there exist Borel mappings $a(t, x), a_{*}(t, x)$ and $\alpha(t, x)$ from $R \times \mathbb{R}^{n}$ to $\mathbb{R}^{n}$ and to $\overline{\mathrm{S}}_{+}$, respectively, such that $D \xi(t)=a(t, \xi(t)), D_{*} \xi(t)=a_{*}(t, \xi(t))$ and $D_{2} \xi(t)=\alpha(t, \xi(t))$. Following [7] we call $a(t, x), a_{*}(t, x)$ and $\alpha(t, x)$ the regressions.

Let Borel measurable mappings $a(t, x)$ and $\alpha(t, x)$ from $[0, T] \times \mathbb{R}^{n}$ to $\mathbb{R}^{n}$ and to $\overline{\mathrm{S}}_{+}(n)$, respectively, be given. We call the system of the form

$$
\left\{\begin{array}{l}
D \xi(t)=a(t, \xi(t)) \\
D_{2} \xi(t)=\alpha(t, \xi(t))
\end{array}\right.
$$

a first order differential equation with forward mean derivatives.

Definition 2. We say that (4) has a solution on $[0, T]$ with initial condition $\xi(0)=x_{0}$, if there exist a probability space $(\Omega, \mathcal{F}, \mathrm{P})$ and a process $\xi(t)$ given on $(\Omega, \mathcal{F}, \mathrm{P})$ and taking values in $\mathbb{R}^{n}$ such that $\mathrm{P}$-a.s. and for almost all $t$ (4) is satisfied.

Several existence of solution theorems for (4) can be found in [6].

Definition 3. The smooth function $\varphi: X \rightarrow \mathbb{R}$ sending the topological space $X$ to $\mathbb{R}$ is called proper if the preimage of every relatively compact set in $\mathbb{R}$ is relatively compact in $X$.

Denote by $\mathcal{L}$ the generator of Markov process generated by equation (4).

Theorem 1. Let on $\mathbb{R}^{n}$ there exist a smooth proper positive function $\varphi: X \rightarrow \mathbb{R}$ such that $\mathcal{L} \varphi<C$ for all $t \in\left[0,+\infty\right.$ and $x \in \mathbb{R}^{n}$ where $C>0$ is a certain real constant. Then the flow generated by equation (4) is complete, i.e. all solutions of (4) with deterministic initial values exist for $t \in[0,+\infty)$.

Theorem 1 is a reformulation of [8, Theorem IX. 6A].

\section{Differential Equations with Backward Mean Derivatives}

The system

$$
\left\{\begin{array}{l}
D_{*} \xi(t)=a(t, \xi(t)) \\
D_{2} \xi(t)=\alpha(t, \xi(t))
\end{array}\right.
$$

is called a first order differential equation with backward mean derivatives. 
Notice that we do not introduce the notion of backward analog of operator $D_{2}$ since, applying the properties of Itô integral, one can easily prove that for a diffusion process $\xi(t)$ the result of application of that analog coincides with $D_{2} \xi(t)$ (this follows from the results of $[2,3])$.

Definition 4. We say that (5) has a solution on $[0, T]$ with condition $\xi(T)=\xi_{0}$, if there exist a probability space $(\Omega, \mathcal{F}, \mathrm{P})$ and a process $\xi(t)$ given on $(\Omega, \mathcal{F}, \mathrm{P})$ and taking values in $\mathbb{R}^{n}$ such that $\xi(T)=\xi_{0}$, P-a.s. and for almost all $t$ equality (5) is satisfied.

Consider a solution $\eta(t)$, given on $t \in[0, T]$, with initial condition $\eta(0)=\xi_{0} \in \mathbb{R}^{n}$ of the following differential equation with forward mean derivatives

$$
\left\{\begin{array}{l}
D \eta(t)=-a(T-t, \eta(t)), \\
D_{2} \eta(t)=\alpha(T-t, \eta(t)) .
\end{array}\right.
$$

Theorem 2. The process $\xi(t)=\eta(T-t)$ is a solution of (5) with condition $\xi(T)=\xi_{0}$, where $\eta(t)$ is a solution of (6) with initial condition $\eta(0)=\xi_{0}$.

Indeed, $D_{*} \xi(t)=-D \eta(T-t)=a(t, \eta(T-t))=a(t, \xi(t))$. For $D_{2} \xi(t)$ the arguments are analogous. The equality $\xi(T)=\xi_{0}$ is obvious.

Now we are in position to find conditions, under which solutions of (5) exist on every interval $[0, T]$. It is evident that for this it is enough to show that the flow generated by equation (6), is complete. Denote the generator of $(6)$ by $\tilde{\mathcal{L}}$.

Theorem 3. If on $\mathbb{R}^{n}$ there exists a smooth proper positive function $\varphi: \mathbb{R}^{n} \rightarrow \mathbb{R}$ such that $\tilde{\mathcal{L}} \varphi<C$ for some real $C>0$ at all $t \in[0,+\infty)$ and $x \in \mathbb{R}^{n}$, then all solutions of (5) with deterministic values of "inverse" Cauchy problem exist on every interval $[0, T]$.

Theorem 3 follows from Theoren 1 and Theorem 2 .

The research is supported in part by RFBR Grant 18-01-00048.

\section{References}

1. Nelson E. Derivation of the Schrödinger Equation from Newtonian Mechanics. Physical Review, 1966, vol. 150, pp. 1079-1085. DOI: 10.1103/PhysRev.150.1079.

2. Nelson E. Dynamical Theory of Brownian Motion. Princeton NJ, Princeton University Press, 1967.

3. Nelson E. Quantum Fluctuations. Princeton NJ, Princeton University Press, 1985.

4. Gliklikh Yu. E. Deterministic Viscous Hydrodynamics Via Stochastic Analysis on Groups of Diffeomorphisms. Methods Funct. Anal. Topology, 2003, vol. 9, no. 3, pp. 146-153.

5. Gliklikh Yu. E. Global and Stochastic Analysis with Applications to Mathematical Physics. London, Springer-Verlag, 2011. DOI: 10.1007/978-0-85729-163-9.

6. Azarina S. V., Gliklikh Yu. E. Differential Inclusions with Mean Derivatives. Dynamic Systems and Applications, 2007, vol. 16, no. 1, pp. 49-71. 
7. Parthasarathy K. R. Introduction to Probability and Measure. New York, SpringerVerlag, 2005. DOI: 10.1007/978-93-86279-27-9.

8. Elworthy K. D. Stochastic Differential Equations on Manifolds. Probability Towards 2000. Lecture Notes in Statistics, vol. 128. New York, Springer, NY. DOI: 10.1007/9781-4612-2224-8_10.

Yuri E. Gliklikh, DSc (Math), Full Professor, Mathematics Faculty, Voronezh State University (Voronezh, Russian Federation), yeg@math.vsu.ru.

Nikita V. Zakharov, Postgraduate Student, Mathematics Faculty, Voronezh State University (Voronezh, Russian Federation), punk74@rambler.ru.

Received October 10, 2018.

УДК 519.216

DOI: $10.14529 /$ jcem180406

\title{
О ГЛОБАЛЬНОМ ПО ВРЕМЕНИ СУЩЕСТВОВАНИИ РЕШЕНИЙ СТОХАСТИЧЕСКИХ УРАВНЕНИЙ С ПРОИЗВОДНЫМИ В СРЕДНЕМ СЛЕВА
}

\author{
Ю. Е. Гликлих, Н. В. Захаров
}

Понятие производных в среднем было введено Э. Нельсоном в 60-х годах ХХ столетия, и в настоящее время имеется много математических моделей физических и технических процессов в терминах уравнений с указанными производными. Эта статья посвящена изучению стохастических дифференциальных уравнений с производными в среднем слева. Этот тип уравнений возникает в некоторых моделях физических и технических процессов, и, таким образом, его изучение важно для приложений. Но, с другой стороны, изучение таких уравнений требует новых методов и идей. В этой статье мы имеем дело со свойством глобального по времени существования всех решений «обратной» задачи Коши для уравнений с производными в среднем слева. Найдено условие, которое гарантирует глобальное по времени существование указанных решений. Этот результат важен для многих математических моделей физических и технических процессов.

Ключевые слова: производные в среднем слева; стохастические уравнения; существование глобальных решений.

\section{Литература}

1. Nelson, E. Derivation of the Schrödinger Equation from Newtonian Mechanics E. Nelson // Physical Review. - 1966. - V. 150. - P. 1079-1085.

2. Nelson, E. Dynamical Theory of Brownian Motion / E. Nelson. - Princeton, NJ: Princeton University Press, 1967.

3. Nelson, E. Quantum Fluctuations / E. Nelson. - Princeton, NJ: Princeton University Press, 1985. 
4. Gliklikh, Yu. E. Deterministic Viscous Hydrodynamics via Stochastic Analysis on Groups of Diffeomorphisms / Yu. E. Gliklikh // Methods Funct. Anal. Topology. 2003. - V. 9, № 3. - P. 146-153.

5. Gliklikh, Yu. E. Global and Stochastic Analysis with Applications to Mathematical Physics / Yu. E. Gliklikh. - London: Springer-Verlag, 2011.

6. Azarina, S. V. Differential Inclusions with Mean Derivatives / S. V. Azarina, Yu. E. Gliklikh // Dynamic Systems and Applications. - 2007. - V. 16, № 1. - P. 49-71.

7. Партасарати, К. Р. Введение в теорию вероятностей и теорию меры / К. Р. Партасарати. - М.: Мир, 1988.

8. Elworthy K. D. Stochastic Differential Equations on Manifolds / K. D. Elworthy // Probability Towards 2000. Lecture Notes in Statistics, vol. 128. - NY: Springer.

Гликлих Юрий Евгенъевич, доктор физико-математических наук, профессор, математический факультет, Воронежский государственный университет (г. Воронеж, Российская Федерачия), уеg@math.vsu.ru.

Захаров Никита Вячеславович, аспирант, математический факультет, Воронежский государственный университет (г. Воронеж, Российская Федераиия), punk74@rambler.ru.

Поступила в редакцию 10 октября 2018 г. 